\title{
Understanding RFID Technology within a Business Intelligence Framework
}

\author{
Richard Herschel, Patricia D. Rafferty \\ Erivan K. Haub School of Business, Saint Joseph’s University, Philadelphia, USA \\ Email: patricia.rafferty@sju.edu
}

Received August 22, 2012; revised September 3, 2012; accepted September 10, 2012

\begin{abstract}
Radio Frequency Identification (RFID) technology provides new and exciting opportunities for increasing organizational, financial, and operational performance. With its focus on organizational efficiency and effectiveness, RFID technology is superior to barcodes in its ability to provide source automation features that increase the speed and volume of data collection for analysis. Today, applications that employ RFID are growing rapidly and this technology is in a continuous state of evolution and growth. As it continues to progress, RFID provides us with new opportunities to use business intelligence (BI) to monitor organizational operations and learn more about markets, as well as consumer attitudes, behaviors, and product preferences. This technology can even be used to prevent potentially faulty or spoiled products from ending up in the hands of consumers. However, RFID offers significant challenges to organizations that attempt to employ this technology. Most significantly, there exists the potential for RFID to overwhelm data collection and BI analytic efforts if organizations fail to effectively address RFID data integration issues. To this end, the purpose of this article is to explicate the dynamic technology of RFID and how it is being used today. Additionally, this article will provide insights into how RFID technology is evolving and how this technology relates to BI and issues related to data integration. This knowledge has never been more essential. While IT academic research into RFID development and issues has declined in recent years, RFID continues to be a vital area of exploration, especially as it relates to BI in the 21st century.
\end{abstract}

Keywords: Business Intelligence; Radio Frequency Identification Technology; Organizational Performance; Data Integration; Data Analytics; Supply Chain Technology; Barcode Data

\section{Introduction}

There has been substantial academic research conducted on Radio Frequency Identification (RFID) technology, along with its capacity to enhance organizational decision-making. Some of this research has focused on RFID and information systems; however, this has diminished as a topic of examination over recent years. This is unfortunate and ill timed, as there have recently been many noteworthy developments and issues that warrant scrutiny, especially with regard to the relationship between RFID and business intelligence.

RFID has been identified as one of the most important technologies of the 21st century because it allows for real-time tracking of objects or products within the supply chain [1]. RFID is a wireless technology that incurporates a tag containing a chip and an antenna for sending and receiving data. The technology interfaces with an interrogator (reader), which has an antenna that communicates with the tag. Middleware then manages, filters, aggregates, and routes the data captured from the tag to the organization's enterprise systems for storages and analyses [2]. This type of technology offers an improved alternative to barcodes. For example, scanning barcodes requires labor, which is costly. Because it is more expensive to collect information via barcodes, retail companies typically conduct inventory counts only once or twice a year, often yielding inaccurate data despite these costly efforts. However, inventory accuracy for apparel stores averages just 65 percent. Unfortunately, this problem just scratches the surface. Retailers consistently have a lack of meaningful and high-volume data regarding the movement of goods from their warehouse to the back of the store, then on to store shelves. Barcodes are not typically scanned when items arrive at the warehouse, nor when they are shipped to a store, arrive at that store, when the items are placed at a particular location within the confines of the store, including the store's selling area. As a result, retailers lack the information and knowledge of how long these processes take to complete or how well the stores are executing these tasks [3].

Similarly, barcode data cannot provide information as to whether an item did not sell because it was unpopular 
with shoppers or because it was simply missing from the shelves when shoppers were ready to buy. This inability to accurately measure product sales success is one of the most fundamental questions for retail operations today; however, barcode technology does not address this essential question, thus hindering meaningful merchandiseing improvements.

These impediments are readily overcome by RFID technology because, unlike barcodes, RFID is not constrained by a need for line-of-sight reading and multiple RFID tags can be read simultaneously. Similarly, RFID tags can store critical information regarding the individual item, can be read in a dirty environment, and have the potential as reusable data containers since they have the potential to be written multiple times. These resultant advantages to barcodes have made RFID a critical component to an enterprise's data supply chain. RFID automates data collection for goods and services, which allows for the application of both automated and ad hoc analytics. This drives drive decision-making capacity that seeks to enhance organizational and process-oriented effectiveness and efficiency [3].

This organizational and process-oriented effectiveness and efficiency is most apparent in RFID technology's capacity to function on a proximity basis. RFID tags can be read and processed as long as they pass within a given radius of a RFID reader. Unlike barcode technologies, where each barcode tag must pass directly in front of a reader, hundreds of RFID tags can be read simultaneously, since there is no requirement for line-of-sight scanning of each tag. In shipping applications, this enables scanning and tracking to be done at a palette level, with tagged items remaining snuggly packaged in a box or shipping crate. RFID eliminates the need to scan each tag on a one-by-one basis. This ease and enhanced speed of data collection affords firms the opportunity to use BI more rapidly, as well as exploit or correct situations that have a direct impact on enterprise performance.

\section{The Evolution of RFID}

Predominantly used in the consumer goods industry [4], RFID technology continues to evolve. Today's enterprises now employ RFID data for many diverse applications, including airline luggage tracking, electronic security, asset tracking, and supply-chain management [5]. Other uses for RFID include monitoring out-of-stock merchandise, product distribution, receiving documentation, proof of delivery, asset management, product life cycle tracking, recall management, product rotation, inventory and shipping accuracy, inventory management, product shrinkage, military applications, and service sector applications [6-9]. Facebook is experimenting with RFID chips embedded in wristbands or badges that allows its members to carry out a variety of social net- working tasks without the need for a computer or smartphone [10].

Many governments and academic institutions now utilize RFID tags. For example, RFID technology is being adopted for such applications such as tracking farm animals, non-stop road tolling, library and document tagging, and national ID cards and passports. Colleges and universities are beginning to implement RFID identification for attendance and alert solutions. For example, Scholar Chip, a New York-based provider of RFID attendance and payment solutions, has issued close to 750,000 RFID tags in various formats, such as ID cards, fobs and stickers. Students hold their RFID-enabled ID badges to readers as they enter the school building, and again as they enter classrooms, where readers are mounted on teachers' desks. Additionally, Universidad Regiomontana in Mexico is using RFID technology to prevent theft of laptop computers issued to staff and faculty [11].

Further examples of loss/theft protection is apparent in the manner in which RFID tags are poised to provide anti-theft for laptops and tablet computers using a Wi-Fi tag. Ekahau, a provider of Wi-Fi-based real-time location system solutions, has announced the launch of a Wi-Fi tag that incorporates a location-tracking device designed to prevent laptop theft and misplacement. The RFID embedded device is a small, flat unit that is plugged into an ExpressCard and can be activated via a few keystrokes. The tag is designed to track and manage the tags anywhere on a campus equipped with Wi-Fi coverage. By determining a tag's location and status, the system can alert a user if a laptop or tablet computer leaves a designated area, or enters an unsecured area [12].

\subsection{RFID and the IT Organization}

IT organizations are also becoming a major consumer of RFID technology. Market revenue for RFID tags, hardware (such as readers and printers), software and middleware, and integration services used to track and trace IT assets within data centers reached $\$ 96.3$ million in 2011. Revenue is expected to grow to $\$ 952.6$ million in 2017, due to the widespread implementation of RFID technology in data centers globally. RFID tags can quickly locate and track innumerable servers and vast numbers of data tapes within large data centers, thus lowering their replacement expenses. Likewise, the lack of asset visibility sometimes results in the duplication of existing assets, ultimately adding to total costs. RFID technology can eliminate this duplication, thus providing significant savings, as well as preventing theft and loss through real-time tracking [13].

RFID provides opportunities for organizations to realize cost efficiencies and effectiveness as they seek to streamline their physical processes. Roberti [14] suggests 
five ways RFID technology facilitates these objectives:

- Deploying RFID to track the 7 - 10 percent of shipping containers typically replaced annually because they are lost or damaged;

- Tagging IT assets with RFID tags instead of bar codes enables more efficiency for tracking and accounting;

- Providing suppliers with RFID tags to be placed on shipments so that the manufacturer can more efficiently and more accurately associate them with parts, raw materials, or products;

- Using RFID to track rental equipment utilization;

- Deploying RFID on subassemblies, large parts, and parts bins to increase throughput with less labor and costs associated with locating parts and subassemblies.

\subsection{RFID Growth Potential}

The number of RFID applications continues to present unbounded opportunities, with diverse industries applying this technology throughout the world. In 2006, cumulative sales of RFID tags reached $\$ 2.4$ billion (USD) [15]. In 2011, the value of the entire RFID market was $\$ 5.84$ billion (USD), up from $\$ 5.63$ billion (USD) in 2010 [16]. RFID market value continued to grow in early 2012, where the cumulative number of RFID tags sold was 15.1 billion, 20 percent of which were sold last year [13].

Even with this unprecedented growth, the RFID market is predicted to grow steadily over the next decade, rising four-fold within that period to \$26.19 billion (UDD) in 2022. A recent research report entitled "Global RFID Market Forecast to 2014” states that the RFID market is expected to grow at a compound annual growth rate of around 18\% through 2014 to reach approximately USD 19.3 billion. It also notes that the RFID market in the Asia-Pacific is growing at a faster rate than those of Europe and America [17]. Further, according to ABI Research, it is expected that $\$ 70.5$ billion will be generated between 2012 and 2017 from sales of RFID readers, transponders, software and services, with sixty percent of the accumulated revenue over the next five years being generated from government, retail, transportation and logistics. These four sectors have been identified by ABI as the most valuable sectors for RFID growth potential. The market is expected to grow 20 percent, year over year, per annum [18].

To foster the further growth in the deployment of this technology, new and cheaper RFID chips are now under development. For example, microelectronics developer, Terepac, reports that it plans to begin manufacturing a "near field communication" (NFC) RFID tag that is expected to be the world's smallest RFID tag. This tag would be cheaper and much smaller than other NFC tags currently on the market, and thus could be embedded in almost any paper label, product or item. The tag could be interrogated via an NFC reader in a user's mobile phone, thereby making it possible to link a customer with information regarding a particular product, or link an individual with a social-networking site, medication data or other Web-based information [19].

\subsection{The Future of RFID Technology}

At MIT, Bhattacharyya, Di Leo, Floerkemeier, Sarma and Anand [20] are working on an inexpensive, passive RFID chip that may dramatically enhance data collection on the status of food items requiring refrigeration. Their research reports on the design of a temperature RFID threshold sensor that registers the violation of critical temperature thresholds by inducing a permanent change in an RFID tag antenna's electrical properties. This inexpensive sensing tag would be useful in monitoring the state of certain items, such as perishable food produce or other fragile goods that must maintain a constant temperature threshold at all times. The sensor would provide the RFID user with binary state information indicating whether critical temperature thresholds were reached during transportation allowing the user to make a decision of whether to keep or discard the goods. Since the state of most goods are examined at the distribution centers in a supply chain, rather than in transit, this type of RFID advancement would dramatically improve realtime monitoring for items, such as orange juice cartons, milk and meat products. Within supply chain applications, an accurate and timely assessment of the state of the product will be automatically monitored as soon as the products pass an RFID reader at the dock door of a distribution center.

These types of examples illustrate the manner in which RFID technology continues to evolve and innovate at an unprecedented rate, not only in the design of the technology, but also in its application. In 2011, the RFID journal reported 101 innovative ways to use RFID [21]. New RFID applications include saving endangered species, smart supermarket carts, liquor pouring tracking at bars, protecting miners, cigarette smoking cessation programs, at-home pain management, and the detection of gunfire.

\section{RFID Technology and Academic Research}

RFID technology has been an exciting area for academic study due to its relative novelty and exploding growth [22]. Scholarly and practitioner-based exploration into RFID technology has led to the emergence of a new research area that builds on existing study in a host of diverse disciplines, such as electronic engineering, infor- 
mation systems, computer science, and business strategy. This has resulted in a significant increase in the number of scholarly papers on RFID in research journals from 1995 to 2005. During this time, topical areas of research provided a general view of the use of RFID technology in the areas of retail and supply chains. This research also dealt with the potential of utilizing RFID technology, the perceived benefits, effects, and challenges for retailers, how consumers are likely to respond to the technology, and the market drivers for RFID implementation in the grocery industry. Within this 10 -year period, the majority of research had been published in technical journals, but it is expected that papers related to RFID technology will continue to grow in management and other business journals.

Bendavid, Lefebvre, Lefebver, \& Fosso-Wamba [4] note that RFID has been a topic of interest in various fields of research related to the technology itself, such as: 1) Innovation management and potential trajectories for RFID adoption; 2) Implementation in an inter-organizational context; 3) Customer relationship management (CRM); 4) Product lifecycle management (PLM); 5) Reverse supply chain activities (e.g., returned goods); and 6) Supply chain management. Recent research has also investigated the impact of RFID technology on retail sales and service operations. For example De Marco, Caglian, De Marco, Caglian, Nervo, and Rafele [23] found that sales growth resulted from the dynamic and integrated impacts of RFID technology, especially in the areas of improved inventory control, faster inventory turnover, and longer time available for store personnel to assist consumers as an effect of more efficient backroom operations.

Ferrer, Dew, and Apte [9] studied several different RFID applications within the service sector to discover how this technology can be used to enhance various aspects of the service delivery, as well as the costs and benefits realized form this technology. Their research reveals how RFID impacts service operations in a variety of scenarios. The authors note that decisions about the selection of new technologies, such as RFID, require significant investment and can have a strategic impact on the organization. To ensure that the right RFID configuration is selected, Ferrer et al. assert that management must be an informed consumer of the technology in order to understand how the data adds value to their operations. In their investigation of RFID utilization in service industries, Ferrer et al. identify four benefits that RFID applications provide, including: 1) Replacement of labor through automation; 2) Cycle time reductions; 3) Enabling self-service; and 4) Advances in loss prevention. They argue that these benefits lead to better control and lower costs.

Baars, Kemper, Lasi, and Siegel [24] find that the dominant focus of RFID research today deals with in- creasing local efficiency gains by implementing a more efficient handling of items or pallets, along with a reduction of processing times. However, while substantial benefits are expected to result from the sharing and processing of RFID data along the supply chain, Baars et al. argue that these applications do not yet take the full potential of RFID data into account. They argue that RFID also requires integrating, enriching and analyzing RFID data for the purpose of supporting decision makers. Supporting data-driven decision making means paying special attention to how RFID technology affects and supports the use of business intelligence capabilities within an organization.

\section{BI and RFID Technology}

BI is widely adopted in organizations and successful BI initiatives have been undertaken across major industries and for varied applications, including health care [25,26], security and event management [27], telecommunications [28], web analytics [29], and Six Sigma [30].

Herschel [31] defines BI as the application of data, technology, and analytics in the pursuit of insights and knowledge that enables decisions and actions that yield value for a firm. He asserts that BI creates value by providing evidence that organizations can use to make informed decisions about people, processes, products and services. Herschel's definition suggests that because RFID technology has inherent capabilities for capturing and transmitting product data for decision-making, it should be seen as an important data source for BI.

Figure 1 presents a vision of BI as an integrative application of technologies, models, techniques, and practices. In Miori and Klimberg's [32] framework, each of the three circles of the Venn diagram represent applications that had previously been considered quite distinct, which include 1) information systems and technology,

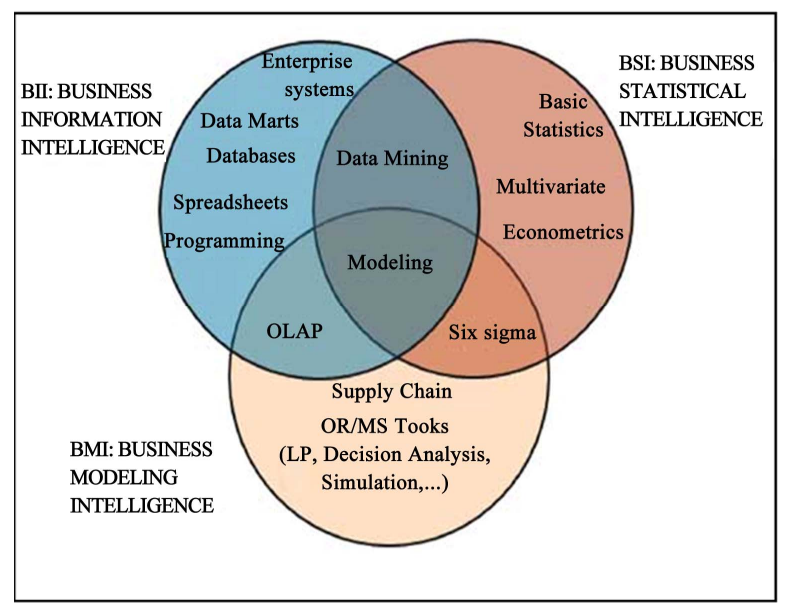

Figure 1. Business intelligence/business analytics breakdown (Klimberg \& Miori, 2010). 
2) statistics, and 3) operation research/management science.

This framework serves to encapsulate a broad definition of BI, where BI is characterized from each of three viewpoints, which consist of 1) business information intelligence (BII), 2) business statistical intelligence (BSI) and 3) business modeling intelligence (BMI). Each of these three viewpoints has particular business aspects that are independent of the other viewpoints. Conversely, each viewpoint can work together or utilize techniques/skills from one or possibly two of the other disciplines. For example, data mining, which requires a high level of statistical knowledge as well as the availability of necessary data, may require significant IT skills and/or knowledge. Further, if data mining analysis demands a systematic process of analysis, modeling skills may be required. Within the context of this framework, data provided by RFID would be secured by IT technology and then be subjected to statistics and modeling analytics to derive understanding of the data so as to affect decision-making.

\subsection{RFID Technology and Decision-Making}

The confluence of business intelligence and RFID technology is best illustrated in the manner in which BI provides the means by which RFID data can influence business processes and decision-making. $\mathrm{BI}$ also provides the underlying architectures, tools, databases, applications, and methodologies that support RFID technology and its ability to positively affect organizational processes [33]. Within this context, the major objectives of BI are to enable interactive and easy access to diverse data, to enable manipulation and transformation of this data, and to provide business managers and analysts with the ability to conduct appropriate analyses for actionable execution [28]. BI is seen as a data-centric approach that relies on advanced data collection, extraction, and analysis technologies [34].

Since data warehousing is the foundation of BI, the design of data marts and tools for extraction, transformation, and load (ETL) are essential for converting and integrating enterprise-specific data. Database query, online analytical processing (OLAP), and advanced reporting tools are typically adopted to explore important data characteristics. Business performance management (BPM) tools, such as scorecards and dashboards, are often used in BI to analyze and visualize various performance metrics. In addition to the business analytics functions inherent in BI software, advanced knowledge discovery using data and text mining are usually adopted for association rule mining, database segmentation and clustering, anomaly detection, and predictive modeling in various business applications. BI technologies provide historical, current, and predictive views of business operations to enhance the comprehension/understanding of fact-based interrelationships and this makes BI an enabling technology for knowledge creation [35].

Within the context of BI, the better the data, the more accurate are the results of the analytics that employ the data. This in turn leads to more informed and (hopefully) better decision-making [36]. In BI, the ideal means for capturing data is via source automation, since this process increases both the efficiency and the accuracy of data entry and it is cost effective because it eliminates much of the effort and delay caused when data must be transcribed. RFID technology is a source automation vehicle since it provides an automated, efficient, cost-effective means of providing accurate data for BI evidence-based decision making. RFID data is used to build up an "internet of things", which can be viewed as a network that allows companies to track goods through the global supply chain and execute many applications simultaneously [37]. In addition, RFID source automation capabilities deliver data that BI can use to prevent potential economic damage caused by product piracy. This is possible because RFID tag data is effectively used for product authentication in the supply chain [38].

\subsection{Affiliated Costs}

However, both data quality and availability depend, in part, upon the cost of acquiring the data. Much of the cost for data is derived from getting the data out of source systems (extract), and transforming it to make it consistent across all the various dimensions (transform), and then putting it in a model that is easy to query and analyze (load). Data accuracy inevitably affects task accuracy and the time spent solving a problem [39].

Consequently, there is a cost for placing RFID tags on products to capture data. The RFID Journal [40] notes that most companies that sell RFID tags do not quote prices because pricing is based on: 1) Volume; 2) the amount of memory on the tag; 3 ) the packaging of the tag, for instance whether it's encased in plastic or embedded in a label; 4) whether the tag is active or passive, and other dimensions. In general, active tags are priced at \$25 and up. An active tag is equipped with a battery that can be used as a partial or complete source of power for the tag's circuitry and antenna. However, active tags with special protective housing, extra-long battery life, or sensors can cost $\$ 100$ or more. A passive tag is an RFID tag that does not contain a battery and relies on a tag reader that supplies the power. The price for these chips range from seven to 15 US cents. However, the RFID Journal notes that if the passive tag is embedded in a thermal transfer label on which companies can print a bar code, the price rises to 15 cents and up. 


\section{BI and Data Integration}

Within the context of BI, RFID technology provides a plethora of new data for collection and analysis. However, Edwards [41] asserts that integrating RFID-generated data into BI and other business applications so that essential information can be viewed, analyzed, applied, and presented to end users is often more difficult than assembling the data. Since RFID is used in diverse ways by a variety of organizations and with many different applications, it is problematic to create a single, all-purpose RFID data-integration strategy. This leads many businesses to develop unique integration concepts and tools, or to adopt an amalgamation of approaches used by other organizations that end up thwarting analytic efforts.

In order to enable a more effective relationship between BI and RFID technology, organizations will need to pay more attention to RFID and data integration. To accomplish this, firms will need to better understand RFID technologies and practices, how the technology can be used to improve business processes, and better understand the nature of RFID data. For example, the use of RFID often requires the serialization of products or other assets, which means that RFID adopters need to give individual items a unique serial number, instead of describing them by name or by using randomly allocated numbers. Also RFID enabled real-time location data is often difficult for organizations to integrate into existing ERP applications than other types of RFID information.

Consequently, full utilization of RFID technology would require significant business process redesign and the associated development of new and retooled information technology capabilities within an organization [42]. From an information systems perspective, RFID could be viewed as another technology for capturing source data. Although RFID technology holds the promise of process innovations that create significant improvements in supply chain business models, organizations would still face a new, longer-range set of challenges to create significant economic value. These challenges involve the development of information systems solutions that integrate data derived from RFID into business processes; and developing the feedback-loops, such that new sources of information generate more efficient and effective business processes and decision-making.

The potential for RFID to overwhelm data collection and analytic efforts is significant, since the technology continues to evolve and its applications rapidly expand. This means RFID will contribute to the increasing volume and detail of information captured by enterprises. For instance, IBM [43] states that 2.5 quintillion bytes of data are created each day-so much that $90 \%$ of the data in the world today has been created in the last two years alone. This data comes from a plethora of sources and is oftentimes referred to as "big data".

Hence, while RFID provides an important mechanism for fostering new BI applications with a wider range of time- and location-informing data, firms need to better understand RFID technology itself, the data integration issues RFID can create, and decide which BI efforts they want RFID data to support.

\section{Opportunities for Research}

In an era of economic uncertainty, many organizations, both public and private, have looked at options to reduce costs. Many have reduced their workforce and/or outsourced work, which also includes the trend for organizations to move toward cloud computing to reduce their IT costs. RFID technology has the potential to enable firms to further reduce their costs, gain operational efficiencies, and to learn more about their customer behavior and processes.

However, the full potential of RFID technology has yet to be realized, primarily because many organizations are still dependent on bar codes in their source automation applications. Early in the millennium, research institutions and universities forecasted a revolution in identification of goods within a few years, but this never happen. The failure to transition to RFID was not due to the cost of the tags, but rather that retailers had made substantial investments in barcode technology and weren't willing to change just because the new technology was available.

To address the RFID adoption lag, Impinj, a provider of RFID solutions for identifying, locating, and authenticating items, has unveiled a new Store Performance Simulator (SPS). This Web-based analysis tool is designed to enable retailers considering the deployment of RFID technology to perform what-if scenarios. The tool will help retailers better understand if RFID can increase inventory accuracy and improve a store's profitability. The SPS can help retailers begin to understand the impact, not just of RFID technology, but also of adding additional service labor or inventory-management labor, or of shortening their supply chain. Instead of spending tens of thousands of dollars to test results in the real world, organizations can simply perform a virtual simulation. SPS will provide BI capabilities to retailers, allowing them to forecast the impact of using RFID technology on operating profit, inventory accuracy, unit sales and other metrics [44].

In the future, it is expected that RFID will be able to collect sales information by location and fixture within a store. This will make it feasible to test how well an item sold at one location versus another at a different store, and to optimize a store's configuration in order to maximize revenue. Retailers do some of this now, but their 
store configurations are often based on selling price, or on mere guesswork. With hard data about an item's location and sale price, the amount of time that product spends on the floor, and other data that an item-level RFID system can supply, retailers will be able to simulate different store configurations and forecast sales. This, in turn, will provide better BI input and enable retailers to make better, more informed decisions.

Within the BI context, having real data regarding shipping accuracy, replenishment times, pick accuracy, etc., allows companies to measure-and improve-their performance. Moreover, due to the frequency that RFID data can be collected, more efficient BI allows retailers to correct mistakes more rapidly. However, one impedement for the adoption and deployment of RFID technology has been the inconsistent development and adoption of universal standards. There are accepted standards for many facets of RFID, including near-field communication for payment cards and many industrial applications. However, there are still applications where the RFID standards are not uniform. To address this deficiency, the International Standards Organization (ISO) is taking a leading role in developing conclusive, comprehensive RFID standards across the board.

Finally, it must be noted that much of what has been reported in academic information systems journals concerning RFID technology is dated. As RFID growth continues to accelerate, it is clear that there are noteworthy and substantial prospects for academic research. Clearly, there will be ongoing occasions to track and monitor both the successes and failures that occur in RFID development, implementation and application. In addition, there will be substantial opportunities to better understand how RFID technology and BI efforts combine to influence, enhance, or encumber organizational decision-making.

\section{REFERENCES}

[1] C. C. Chao, J. M. Yang and W. Y. Jen, "Determining Technology Trends and Forecasts of RFID by Historical Review and Bibliometric Analysis from 1991 to 2005,” Technovation, Vol. 27, No. 5, 2007, pp. 268-279. doi:10.1016/j.technovation.2006.09.003

[2] J. Curtin, K. Kauffman and F. J., Riggins, "Making the 'MOST' out of RFID Technology: A Research Agenda for the Study of the Adoption, Usage, and Impact of RFID," Information Technology and Management, Vol. 8, No. 2, 2007, pp. 87-110. doi:10.1007/s10799-007-0010-1

[3] C. Riemenschneider, W. Hardgrave and D. Armstrong, “Is There a Business Case for RFID?” Working Paper ITRI-WP091-0507, University of Arkansas, Fayetteville, 2007.

[4] U. Bendavid, E. Lefebvre, L. Lefebvre and S. FossoWamba, "Key Performance Indicators for the Evaluation of RFID-enabled B-B E-Commerce Applications: The Case of a Five-layer Supply Chain,” Information Systems
E-Business Management, Vol. 7, No. 1, 2009, pp. 1-20. doi:10.1007/s10257-008-0092-2

[5] S. F. Tzeng, W. H. Chen and F. Y. Pai, "Evaluating the Business Value of RFID: Evidence from Five Case Studies,” International Journal of Production Economics, Vol. 112, No. 2, 2008, pp. 601-613. doi:10.1016/j.ijpe.2007.05.009

[6] G. Q. Huang, J. S. K. Lau and K. L. Mak, "The Impacts of Sharing Production Information on Supply Chain Dynamics: A Review of the Literature,” International Journal of Production Research, Vol. 41, No. 7, 2003, pp. 1483-1517. doi:10.1080/0020754031000069625

[7] L. Lapide, "RFID: What's in It for the Forecaster?” The Journal of Business Forecasting Methods \& Systems, Vol. 23, No. 2, 2004, pp. 16-20.

[8] B. Oztaysi, S. Baysan and F. Akpinar, "Radio Frequency Identification in Hospitality,” Technovation, Vol. 29, No. 9, 2009, pp. 618-624. doi:10.1016/j.technovation.2009.05.014

[9] G. Ferrer, N. Dew and U. Apte, "When is RFID Right for Your Service?” International Journal of Production Research, Vol. 124, No. 2, 2010, pp. 414-425.

[10] N. Clayton, "Facebook Finds Ways to Shift Social Networking Online,” 2011.

http://blogs.wsj.com/tech-europe/2011/08/05/facebook-find s-ways-shift-social-networking-offline/?KEYWORDS=rfid

[11] M. S. O’Connor, “RFID Goes to School,” 2012. http://www.rfidjournal.com/magazine/article/9577

[12] RFID Journal, “RFID News Roundup,” 2012. http://www.rfidjournal.com/article/view/9692

[13] RFID Journal, “RFID News Roundup,” 2012. http://www.rfidjournal.com/article/articleview/9746/1/1

[14] M. Roberti, “Global Economic Uncertainty and Slower Growth,” RFID Journal, 2011, pp. 6-8.

[15] R. Das, "RFID Tags in 2005-How Many and Where," IDTechEx, New York, 2005

[16] R. Das and P. Harrop, "RFID Forecasts, Players and Opportunities 2011-2021,” 2011. http://www.idtechex.com/research/reports/rfid_forecasts_ players_and_opportunities_2011_2021_000250.asp

[17] RFID World, "ABI Research: RFID Market to Surpass \$70 Billion over Next Five Years,” 2012. http://www.rfidworld.ca/abi-research-rfid-market-to-surp ass-70-billion-over-next-five-years/860

[18] RFID World, "World RFID Market to Reach 20 billion USD in 2014?” 2012.

http://www.rfidworld.ca/world-rfid-market-to-reach-20-bi llion-usd-in-2014/769

[19] C. Swedberg, “Terepac Announces Tiny NFC RFID Tags,” 2012. http://www.rfidjournal.com/article/view/9661

[20] R. Bhattacharyya, C. Di Leo, D. Floerkemeier, S. Sarma and L. Anand, "RFID Tag Antenna Based Temperature Sensing Using Shape Memory Polymer Actuation,” IEEE Sensors Conference, Kona, 1-4 November 2010, pp. 23632368.

[21] "RFID for What? 101 Innovative Ways to Use RFID," RFID Journal, 2011, pp. 11-35. 
[22] E. Ngai, K. Moon, F. Riggins and C. Yi, "RFID Research: An Academic Literature Review (1995-2005) and Future Research Directions,” International Journal of Production Economics, Vol. 112, No. 2, 2008, pp. 510-520. doi:10.1016/j.ijpe.2007.05.004

[23] A. De Marco, A. Cagliano, M. Nervo and C. Rafele, "Using System Dynamics to Assess the Impact of RFID Technology on Retail Operations," International Journal of Production Economics, Vol. 32, No. 1, 2012, pp. 333344. doi:10.1016/j.ijpe.2011.08.009

[24] H. Baars, H. G. Kemper, H. Lasi and M. Siegel, "Combining RFID Technology and Business Intelligence for Supply Chain Optimization: Scenarios for Retail Logistics,” Proceedings of the 41st Hawaii International Conferenceon System Sciences, Waikoloa, 7-10 January 2008, pp. 1-10.

[25] T. A. Carte, A. B. Schwarzkopf, T. M. Shaft and R. W. Zmud, "Advanced Business Intelligence at Cardinal Health," MIS Quarterly Executive, Vol. 4, No. 4, 2005, pp. 413424.

[26] A. Olinsky and P. Schumacher, "Data Mining for Health Care Professionals: MBA Course Projects Resulting in Hospital Improvements," International Journal of Business Intelligence Research, Vol. 1, No. 2, 2010, pp. 30-41. doi:10.4018/jbir.2010040104

[27] K. Lozito, "Mitigating Risk: Analysis of Security Information and Event Management," International Journal of Business Intelligence Research, Vol. 2, No. 2, 2011, pp. 67-75.

[28] E. Turban, S. Sharda, J. E. Aronson and D. King, "Business Intelligence: A Managerial Approach,” Pearson/Prentice Hall, Upper Saddle River, 2008.

[29] L. Iyer and R. Raman, "Intelligent Analytics: Integrating Business Intelligence and Web Analytics," International Journal of Business Intelligence Research, Vol. 2, No. 1, 2011, pp. 31-45.

[30] D. Miller, "Improving Business Intelligence: The Six Sigma Way,” International Journal of Business Intelligence Research, Vol. 2, No. 1, 2010, pp. 31-45.

[31] R. T. Herschel, "Business Intelligence: Opportunities for Research," Proceedings of the 33rd International Conferenceon Information Technology Interfaces, Cavtat, 27-
30 June 2011, pp. 1-5.

[32] R. Klimberg and V. Miori, "Back in Business: OR/MS Today," 2010.

http://www.informs.org/ORMS-Today/Public-Articles/Oc tober-Volume-37-Number5/Back-in-Business

[33] M. Raisinghani, "Business Intelligence in the Digital Economy: Opportunities, Limitations and Risks,” The Idea Group, Hershey, 2004.

[34] H. J. Watson and B. Wixom, "The Current State of Business Intelligence,” IEEE Computer, Vol. 40, No. 9, 2007, pp. 96-99. doi:10.1109/MC.2007.331

[35] D. Steiger, "Decision Support as Knowledge Creation: A Business Intelligence Design Theory,” International Journal of Business Intelligence Research, Vol. 1, No. 1, 2010, pp. 29-47. doi:10.4018/jbir.2010071703

[36] T. Davenport, “Competing on Analytics," Harvard Business Review, Vol. 84, No. 1, 2006, pp. 98-107.

[37] B. Violino, "Leveraging the Internet of Things," RFID Journal, 2005, pp. 1-2.

[38] M. Lehtonen, F. Michahelles and E. Fleisch, "Trust andSecurity in RFID-based Product Authentication Systems," Systems Journal, Vol. 1, No. 2, 2007, pp. 129-144. doi:10.1109/JSYST.2007.909820

[39] D. Biros, J. George and R. Zmud, "Inducing Sensitivity to Deception in Order to Improve Decision Making Performance: A Field Study,” MIS Quarterly, Vol. 26, No. 2, 2002, pp. 119-144. doi:10.2307/4132323

[40] RFID Journal, "How Much Does an RFID Tag Cost Today?” 2011. http://www.rfidjournal.com/faq/20/85

[41] J. Edwards, "Integrating RFID Data with Business Apps: Seven Strategies that Work," RFID Journal, 2012, pp. 14-23.

[42] F. Neiderman, R. Mattieu, R. Morley and L. W. Kwon, "Examining RFID Applications in Supply Chain Management," Communications of the ACM, Vol. 50, No. 7, 2007, pp. 93-101.

[43] IBM, "Brining Big Data to the Enterprise, 2012. http://www-01.ibm.com/software/data/bigdata

[44] M. Roberti, “RFID and Data-Driven Retailing,” 2012. http://www.rfidjournal.com/article/articleview/9621/1/2 